\title{
Transmissivity Changes and Microseismicity Induced by Small- Scale Hydraulic Fracturing Tests in Crystalline Rock
}

\section{Journal Article}

Author(s):

Jalali, Reza (D); Gischig, Valentin; Doetsch, Joseph (D); Näf, Rico; Krietsch, Hannes; Klepikova, Maria; Amann, Florian; Giardini, Domenico

Publication date:

2018-03-16

Permanent link:

https://doi.org/10.3929/ethz-b-000249353

Rights / license:

In Copyright - Non-Commercial Use Permitted

Originally published in:

Geophysical Research Letters 45(5), https://doi.org/10.1002/2017GL076781 


\section{Geophysical Research Letters}

\author{
RESEARCH LETTER \\ 10.1002/2017GL076781 \\ Key Points: \\ - Small-scale hydraulic fracturing \\ produces transmissivity increase in \\ crystalline rock \\ - A systematic correlation between \\ seismic characteristics and \\ transmissivity enhancement is not \\ observed \\ - Fracture size derived from seismicity \\ clouds and hydraulic responses \\ strongly correlated
}

Supporting Information:

- Supporting Information S1

Correspondence to:

M. Jalali,

jalalim@ethz.ch

\section{Citation:}

Jalali, M., Gischig, V., Doetsch, J., Näf, R., Krietsch, H., Klepikova, M., et al. (2018). Transmissivity changes and microseismicity induced by small-scale hydraulic fracturing tests in crystalline rock. Geophysical Research Letters, 45. https://doi.org/10.1002/2017GL076781

Received 18 DEC 2017 Accepted 15 FEB 2018 Accepted article online 20 FEB 2018

(O2018. American Geophysical Union. All Rights Reserved.

\section{Transmissivity Changes and Microseismicity Induced by Small- Scale Hydraulic Fracturing Tests in Crystalline Rock}

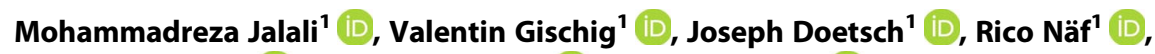 \\ Hannes Krietsch ${ }^{1}$ iD, Maria Klepikova' ${ }^{1}$, Florian Amann ${ }^{2}$ iD, and Domenico Giardini ${ }^{1}$ \\ ${ }^{1}$ Department of Earth Sciences, ETH Zürich, Zürich, Switzerland, ${ }^{2}$ Chair of Engineering Geology and Hydrogeology, RWTH \\ Aachen, Aachen, Germany
}

Abstract Multiple meter-scale hydraulic fracturing (HF) experiments were executed in the crystalline rock at the Grimsel Test Site, Switzerland. The effect of the HF on the rock transmissivity has been quantified with hydraulic tests before and after each HF experiment. We observe transmissivity enhancement of 2 to 3 orders of magnitude and a change in the dominant flow regime after most of the HF tests. From microseismicity induced by the $\mathrm{HF}$, we do not observe a systematic correlation between transmissivity enhancement and event numbers, frequency-magnitude distribution, or maximum magnitude. However, the radii of hydraulic fractures inferred independently from seismicity clouds and hydraulic responses coincide, implying that slip along fractures is the common underlying mechanism for transmissivity increase and seismicity.

\section{Introduction}

The exploitation of subsurface natural resources, such as hydrocarbon and heat, requires that the bearing reservoirs have inherent permeability and connectivity to reach economic productivity. However, in situ permeability is low for certain rock types and typically decreases with depth (Rutqvist \& Stephansson, 2003), affecting reservoir productivity. Numerous stimulation techniques have been developed to increase the permeability of low-permeable reservoirs, such as high-pressure fluid injection, commonly referred to as hydraulic stimulation. Hydraulic stimulation has become a standard method to enhance permeability at depth for exploiting deep geothermal resources or shale gas/oil extraction (Economides \& Nolte, 2000; Evans et al., 2005).

Hydraulic stimulation describes two distinct but related methods, which are (1) initiation and propagation of new fractures (mode I), so-called hydraulic fracturing (HF), and (2) shearing of preexisting fractures (modes II and III), that is, hydraulic shearing (HS). While both methods involve high-pressure fluid injection into hydraulically sealed borehole sections, they differ in the intended mechanism. During HF, short borehole sections, without preexisting fractures, are selected so that fluid pressure initiates a new fracture at the borehole wall and propagates into the rock mass (Hubbert \& Willis, 1972; Economides \& Nolte, 2000). In contrast, during HS operations, larger open holes sections are common, which invariably contain preexisting fractures and/or large fault zones (Evans et al., 2005; Zoback \& Harjes, 1997). Thus, slip is induced by the reduction of effective normal stress along fractures that support shear stress. This is often associated with irreversible dilation as irregularities along the fracture surfaces overlap each other (Lee \& Cho, 2002; Rahman et al., 2002). Note that shearing, fracture formation, and fracture opening may occur concomitantly, and the distinction between them during injection is challenging (Dusseault \& McLennan, 2011; McClure \& Horne, 2014).

A major difference between $\mathrm{HF}$ and $\mathrm{HS}$ is the resulting permeability enhancement; it tends to be irreversible for $\mathrm{HS}$ but is mostly reversible for HF as the fractures almost fully close after depressurization. Several authors (e.g., Arihara et al., 1995; Hart, 2016) observed from hydraulic tests that extensive three-dimensional fracture networks were created during HF experiments but that most of the induced fractures closed after HF. In contrast, Evans et al. (2005) reported a 200-fold permeability enhancement of the major fractures participating in flow and evidence of shear dislocation after hydraulic stimulation in long open-hole sections at the Soultzsous-fôret geothermal field. Also, at the Basel geothermal project, a 400-fold irreversible permeability enhancement was observed after stimulation (Häring et al., 2008). Since during HF, permeability enhancement tends to be reversible, permanent fracture opening is achieved in shale gas fields by flushing sand or other particles (proppants) into the fractures along with the fluid (Gidley et al., 1989). In the context of 
geothermal energy exploitation, HS is the favored method because no proppant, or chemical additives to increase fluid viscosity for better proppant spreading, have to be used.

Both HF and HS are associated with microseismicity. In the case of HS, seismicity is thought to be closely related to permeability enhancement mechanisms, as pressure-induced fracture slip is the predominant source of both phenomena (Evans et al., 2005; Häring et al., 2008; Ishibashi et al., 2016). For HF, the source of seismicity is not as evident and is being discussed in literature. Nolen-Hoeksema and Ruff (2001) suggested that three principle mechanisms may give rise to seismicity during propagation of hydraulic fractures: (1) seismic energy radiated by tensile fracture opening, (2) pressure leak-off and subsequent slip along fractures that intersect the hydraulic fracture, or (3) stress changes around the propagating hydraulic fracture promoting slip of preexisting fractures. In many HF studies from the laboratory scale (Falls et al., 1992) to large-scale field operations (Rutledge et al., 2004), double-couple source mechanisms are predominately found. This indicates that tensile fracturing is of lesser importance as a seismic source, as it would produce strong non-doublecouple focal mechanisms. Thus, the conceptual understanding of a hydraulic fracture being purely tensile and dissecting intact rock seems oversimplified, as the double-couple seismicity implies abundant slip along preexisting fractures-either triggered by pressure fluid leak-off or stress redistribution.

Here we present a series of meter-scale HF experiments in crystalline rock, for which changes in hydraulic properties and microseismicity were systematically recorded and compared. Transmissivity values are used in this manuscript interchangeably with permeability as the hydraulic properties of the injected fluid were kept identical to in situ water. Results are interpreted in light of the interaction of hydraulic with natural fractures. Our study is one of few studies jointly analyzing and comparing microseismicity and hydraulic property changes during hydraulic stimulations (e.g., Evans et al., 2005; Häring et al., 2008).

\section{Study Site}

The HF experiments (Figure 1) were performed at the Grimsel Test Site (GTS) in Switzerland as part of a stress characterization survey (Krietsch et al., 2017) in preparation for a series of hydraulic stimulations referred to as the In situ Stimulation and Circulation (ISC) experiments (Amann et al., 2018). The GTS is located at a depth of $450 \mathrm{~m}$ in crystalline rock, referred to as Aar Granite and Grimsel Granodiorite. The rock mass is dissected by ductile faults $\left(\mathrm{S} 1\right.$ faults, $142^{\circ} / 77^{\circ}$ ), and brittle-ductile faults and fracture zones (S3 faults, $183^{\circ} / 65^{\circ}$ ) (Keusen et al., 1989). The latter is often associated with metamorphosed lamprophyre intrusions, now exposed as biotite-rich zones (i.e., metabasic dikes, Figure 1c). Apart from these persistent large-scale structures, the rock mass contains exceptionally few small-scale fractures $(<1 / \mathrm{m})$. The rock contains a persistent foliation that is subparallel to the $\mathrm{S} 1$ fault zones. The rock is saturated, with water mainly circulating in the shear zones as well as along lamprophyre contacts. A hydrostatic pressure of $0.2-0.3 \mathrm{MPa}$ is observed within these major structures in the tested ISC rock volume, influenced by drainage to the gallery. The average transmissivity of the intact rock is in the range of $10^{-14}-10^{-13} \mathrm{~m}^{2} / \mathrm{s}$, whereas the transmissivity of shear zones ranges from $10^{-12}$ to $10^{-6} \mathrm{~m}^{2} / \mathrm{s}$ (Keusen et al., 1989). The specific storage varies in a range of $10^{-9}-10^{-6} \mathrm{~m}^{-1}$ (IIIman \& Tartakovsky, 2006), which reflects the heterogeneity of the rock volume (Sanchez-Vila et al., 1999).

\section{Methodology}

\subsection{Hydraulic Fracturing Experiments}

$\mathrm{HF}$ tests were performed in $0.7 \mathrm{~m}$ long injection intervals in three boreholes (Figure 1c), with the $11 \mathrm{HF}$ tests distributed in $\mathrm{SBH} 1$ (4 tests that were not considered here because seismic monitoring was not operational), SBH3 (3), and SBH4 (4) boreholes. An additional experiment was performed across the S3 metabasic dike; however, this cannot be considered a typical hydraulic fracture experiment and was designed to be a hydraulic test in a preexisting fracture (HTPF) experiment (Haimson \& Cornet, 2003).

All HF experiments included a fracture initiation phase (breakdown initiation) and several fracture-reopening cycles. A summary of injection rate, pressure and detected number of seismic events, is shown in Figure S1 (see supporting information). The HTPF test at $19.8 \mathrm{~m}$ depth of SBH4 borehole aimed at measuring the fracture normal stress (i.e., jacking pressure). For this test, the injection rate was progressively increased to capture the opening pressure. The interval was revisited at a later stage to refine the determination of the opening pressure. 


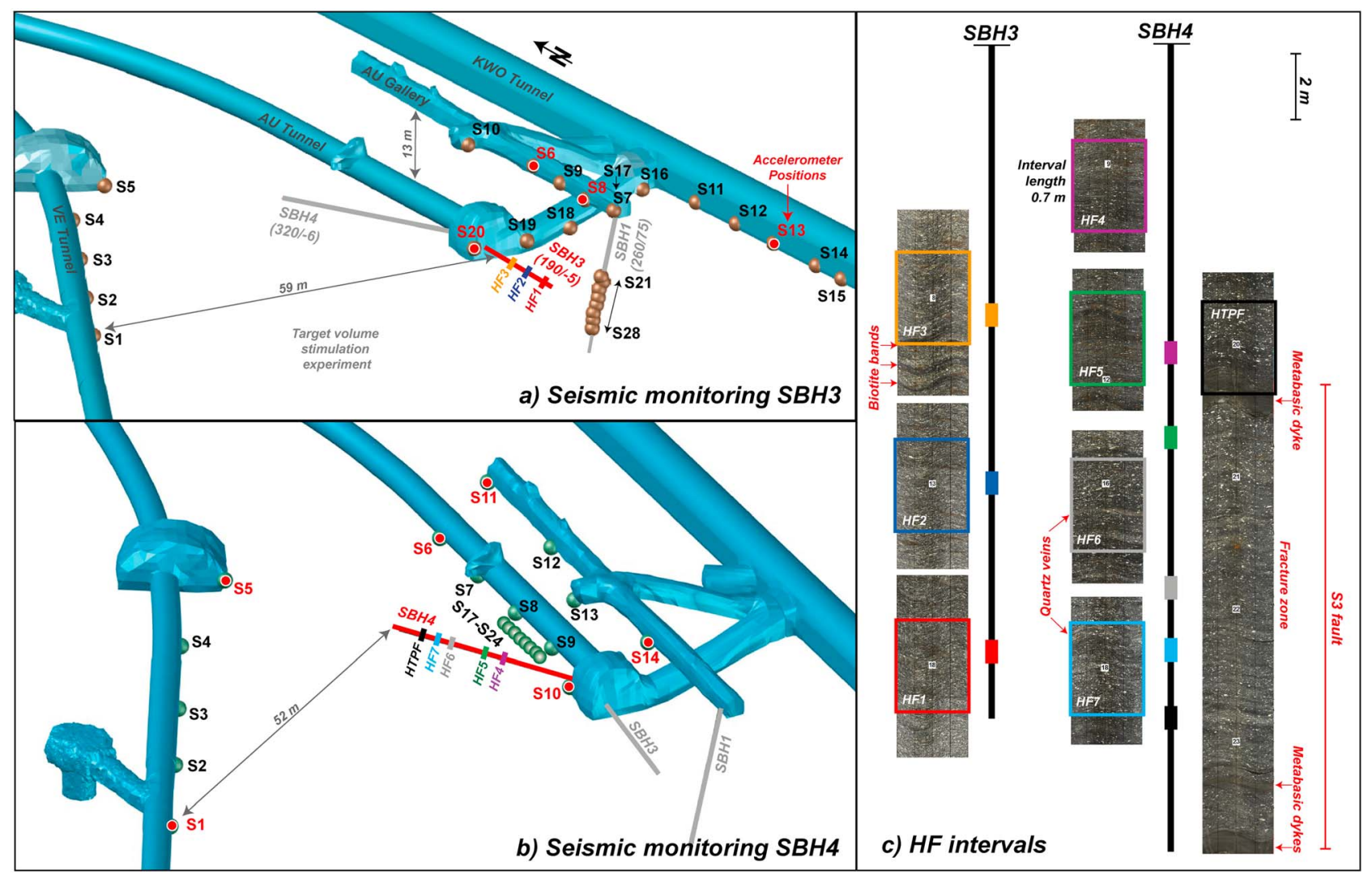

Figure 1. (a) Stress measurement boreholes, drilled from the AU cavern (overburden $450 \mathrm{~m}$ ), along with the seismic network system (sensors S1-S14), used to monitor the HF tests in SBH3 (red sensor positions denote collocated accelerometers). Dip direction and dip (in degrees) are given in brackets; dip is negative if upward inclined. Note that AU gallery is $13 \mathrm{~m}$ and the KWO Tunnel is $5 \mathrm{~m}$ above the level of the AU and VE Tunnel. Together with the borehole sensor array, the tunnel sensors ensure good spatial coverage. (b) The same for HF experiments in SBH4. (c) Optical televiewer (OPTV) images for all HF positions. Three metabasic dikes define the $\mathrm{S} 3$ shear zone at the bottom of $\mathrm{SBH} 4$.

\subsection{Hydraulic Characterization of HF Experiments}

The changes of transmissivity and flow regime were investigated by packer testing before and after each $\mathrm{HF}$ experiment in SBH3 and SBH4 boreholes. Pulse injection (PI) and constant rate injection (CRI) tests were performed with pressures never exceeding $1 \mathrm{MPa}$ to avoid mechanical rock mass responses. During the PI tests, water was injected as a short-period pulse (a couple of seconds). The pressure decay after the perturbation gives an estimate of wellbore storage and interval transmissivity (Cooper et al., 1967). The radius of influence for PI tests is usually in the range of decimeters to meters around the injection borehole, depending on transmissivity and storativity of the rock mass and system compliance. Although uncertainty of this parameter is typically large, an approximate range was calculated based on average values for transmissivity, storativity, and test duration using the relationship by de Marsily (1986). CRI tests include injection with constant flow rates that were used from preliminary hydraulic transmissivity values, estimated from the previously performed PI tests. The test duration ranges from minutes to hours to optimally capture the formation behavior beyond the wellbore storage response area (i.e., beyond the linear section of the pressure derivative curve representing wellbore storage, e.g., Renard et al., 2009). The radius of influence for CRI tests depends on the rock mass transmissivity and storativity, and injection duration. It varies from meters to decameters for tests conducted at the GTS. Thus, the scale of measured hydraulic properties is larger for CRI tests than for PI tests. Note that only PI tests were performed before and after the HF experiments. CRI tests were done only after the experiments.

The transient pressure responses for PI and CRI were analyzed with a combination of analytical and numerical solutions. The transient pressure responses from the PI tests were evaluated by curve matching using the solutions of Cooper et al. (1967) for overdamped slug and pulse tests in homogeneous and isotropic formations (i.e., HF tests), and the Barker and Black's (1983) solution for fractured formations with double 

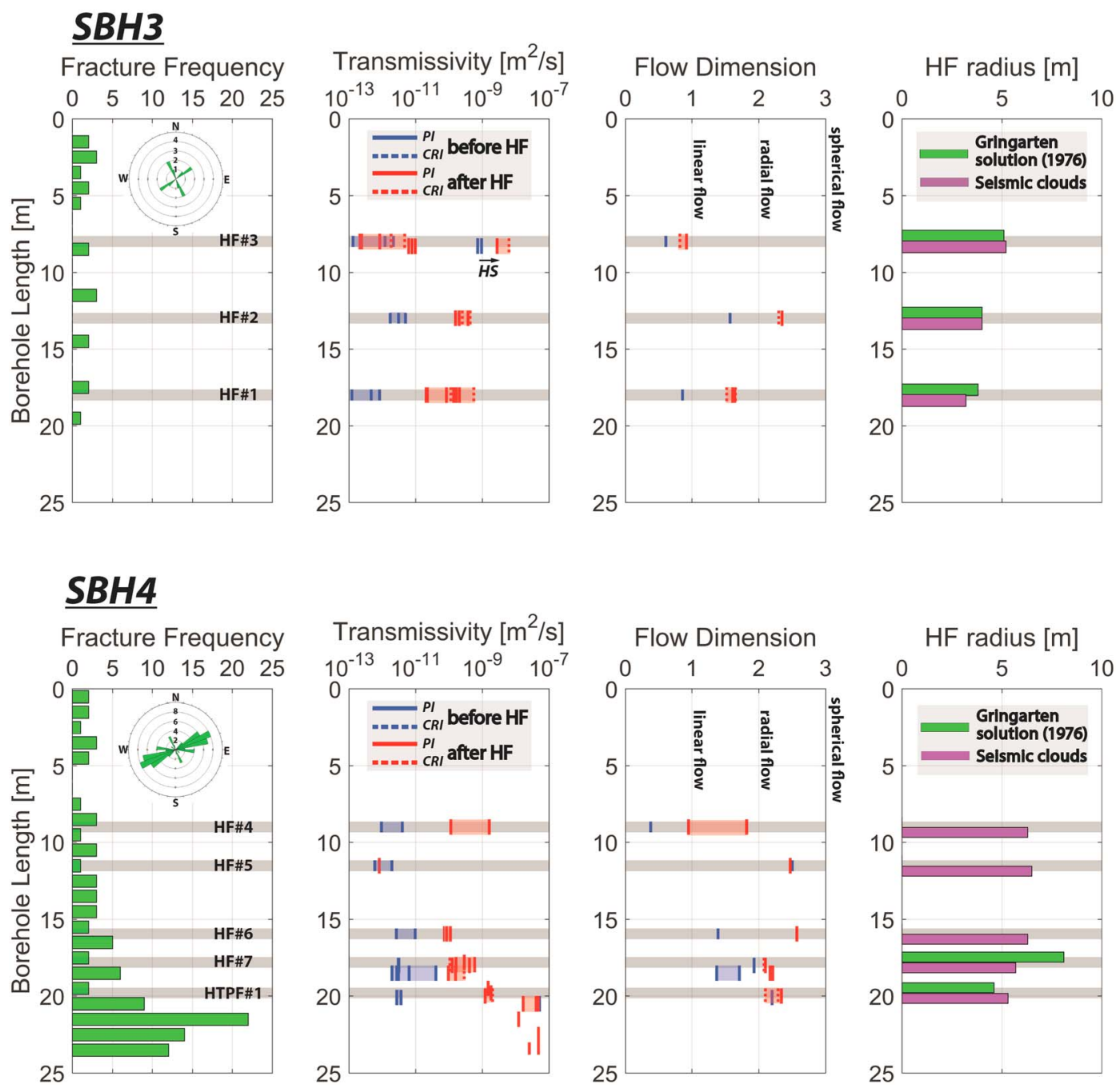

Figure 2. Profiles of fracture frequency, transmissivity, flow dimension, and the estimated radius of hydraulic fractures along the SBH3 (top) and SBH4 (bottom) boreholes. The location of each HF test is shown using the gray bands. Blue and red lines represent the value of hydraulic parameters before and after each HF test, respectively.

porosity and slab blocks where the packed intervals contain multiple fractures (i.e., HTPF test). The CRI tests were first evaluated by straight-line regression in semilog-plot using the Cooper and Jacob (1946) solution for an infinite homogeneous and isotropic formations as well as the Daviau et al. (1988) solution for a horizontal well in non-leaky confined formations. Hydraulic fracture lengths were estimated with the analytical solution of Gringarten and Ramey (1974). Following work of Barker (1988) and Le Borgne et al. (2004), the generalized radial flow model in fractured media was adopted to quantify the dominant flow regime expressed by the fractional, noninteger flow dimension. It describes the geometry of the system by defining the power law relationship between the flow area and the distance from the well, which is a numerical representation of the flow regimes of the area of influence. To estimate the equivalent hydraulic parameters (transmissivity and storativity), the corresponding flow dimension and their uncertainties, all tests were inverted with $\mathrm{n}$ dimensional Statistical Inverse Graphical Hydraulic Test Simulator, nSIGHTS (Roberts, 2006).

\subsection{Microseismic Monitoring}

$\mathrm{HF}$-induced seismicity in $\mathrm{SBH} 3$ and $\mathrm{SBH} 4$ was monitored by a microseismic sensor network that was reconfigured for each borehole (Figures 1a and 1b). The network consists of piezosensors (Type GMuG Ma-Bls-7-70, sensitivity between 1 and $100 \mathrm{kHz}$ ) that were clamped to tunnel walls, as well as an array of eight piezosensors in observation boreholes that were pneumatically pressed against the borehole wall. For monitoring of 
Table 1

Summary of Hydraulic Test Results and Seismicity Characteristics

\begin{tabular}{|c|c|c|c|c|c|c|c|c|c|c|c|c|}
\hline Borehole & Label & $\begin{array}{l}\text { Depth } \\
\text { (m) }\end{array}$ & $\begin{array}{l}\text { Distance to } \\
\text { borehole. } \\
\text { sensors }(m)\end{array}$ & $\begin{array}{l}\text { Injected } \\
\text { volume } \\
\text { (L) }\end{array}$ & $\begin{array}{l}\text { Injection } \\
\text { recovery } \\
(\%)\end{array}$ & $\begin{array}{c}\text { Trans. } \\
\text { before HF } \\
\left(\mathrm{m}^{2} / \mathrm{s}\right)\end{array}$ & $\begin{array}{l}\text { Trans. } \\
\text { after HF } \\
\left(\mathrm{m}^{2} / \mathrm{s}\right)\end{array}$ & $\begin{array}{l}\text { Trans. } \\
\text { change } \\
\text { factor }\end{array}$ & $\begin{array}{l}\text { Detected } \\
\text { events }\end{array}$ & $\begin{array}{l}\text { Located } \\
\text { (\% of all } \\
\text { detected) }\end{array}$ & $\begin{array}{c}\text { \#Events } \mathrm{M}_{\mathrm{A}} \\
\quad>-2.8\end{array}$ & $\begin{array}{c}\text { Max. } \\
M_{A}\end{array}$ \\
\hline \multirow[t]{3}{*}{ SBH3 } & HF1 & 18 & 9.2 & 7.9 & 72 & $3.6 \mathrm{E}-13$ & 1.1E-10 & 300 & 1161 & 13 & 13 & -2.6 \\
\hline & HF2 & 13 & 13.1 & 10.0 & 72 & 3.0E-12 & $2.6 \mathrm{E}-10$ & 90 & 482 & 25 & 18 & -2.3 \\
\hline & $\mathrm{HF}^{*}$ & 8 & 18.2 & 10.4 & 7 & 7.0E-13 & $8.2 \mathrm{E}-13$ & 1 & 274 & 26 & 7 & -2.5 \\
\hline \multirow[t]{5}{*}{ SBH4 } & HF4 & 9 & 5.5 & 10.9 & 41 & $1.9 \mathrm{E}-12$ & $1.1 \mathrm{E}-10$ & 60 & 2258 & 9 & 228 & -2.1 \\
\hline & $\mathrm{HF}^{*}$ & 11.5 & 7.2 & 9.7 & 10 & $5.9 \mathrm{E}-13$ & $8.1 \mathrm{E}-13$ & 1 & 1692 & 23 & 95 & -2.0 \\
\hline & HF6 & 15.9 & 10.2 & 9.1 & 11 & $5.1 \mathrm{E}-12$ & $8.5 \mathrm{E}-11$ & 20 & 772 & 3 & 13 & -2.2 \\
\hline & HF7 & 17.8 & 11.3 & 11.5 & 65 & $3.1 \mathrm{E}-12$ & 1.7E-10 & 60 & 406 & 20 & 56 & -2.0 \\
\hline & HTPF & 19.8 & 12.6 & 28.8 & 2 & 2.4E-12 & 1.7E-09 & 530 & 253 & 23 & 48 & -2.1 \\
\hline
\end{tabular}

Note. The shaded tests (HF3 and HF5) did not show any transmissivity enhancement as fractures may have initiated below the packer (see section 4.1).

the SBH3 experiment, the borehole sensors were installed in SBH1. For the SBH4 experiment, the borehole array was installed in a borehole, parallel to the tunnel, approximately $2 \mathrm{~m}$ away from the tunnel wall. Here the sensor array was repositioned for each HF interval to be as close to the injection interval as possible. Piezosensors were chosen due to their high sensitivity. Because they do not have a well-determined instrument response, some piezosensor positions were additionally equipped with accelerometers (Type Wilcoxon $736 \mathrm{~T}$, sensitivity $2 \mathrm{~Hz}-25 \mathrm{kHz}$ ) that are less sensitive but have a flat instrument response. A series of hammer hits at the tunnel walls were used to retrieve a local estimate of the instrument response, at the positions with piezosensor and accelerometer pairs, as done by Kwiatek et al. (2011) (Figure S3 supporting information). The sampling rate of the 32-channel recording system was set to $1 \mathrm{MHz}$. Detected seismicity was located, as described by Gischig et al. (2018), using a transversely isotropic $P$ wave seismic velocity model that improved locations compared to a isotropic model. The transversely isotropic velocity model was constrained using geological information on foliation, our seismic events (Gischig et al., 2018) as well as active seismic experiments (Doetsch et al., 2017). Location accuracy is on the order of decimeters to meters. Note that the productivity of seismicity (i.e., seismicity rates) cannot be compared between experiments based on detected or located number of events, as these numbers depend on the location of the experiment, with respect to the sensors. Instead, the magnitude distribution, that is, distribution of event sizes, has to be compared. Therefore, we estimate the amplitude magnitude $M_{A}$ based on $P$ wave amplitudes and moment magnitudes $M_{w}$ that could be computed for a subset of events (see supporting information).

\section{Results}

\subsection{Transmissivity Changes}

Hydraulic properties before and after the seven HF and the HTPF tests are provided in Figure 2 and Tables 1 and S1. Fracture frequency in SBH3 is low and unsystematic with a slight increase at depths of less than $5 \mathrm{~m}$ (perhaps related to excavation of the cavern). In SBH4, fracture frequency increases toward the end of the borehole, where it intersects the biotite-rich metabasic dike (Figure 1c). Transmissivity and flow dimensions are shown in blue (before HF) and red (after HF). The solid lines represent the PI tests, whereas dotted lines correspond to CRI tests. The relationship between transmissivities and fracture frequency (e.g., Ando et al., 2003; Illman, 2005; Park et al., 2004; Roques et al., 2016) is presented in Text S3 and Figure S2 (see supporting information).

Transmissivity has increased dramatically for most experiments during HF. The values are based on PI tests only, for which observations before and after HF are available. However, CRI tests confirm the transmissivities of post-HF PI tests. For HF1 and the HTPF, a change in transmissivity by 3 orders of magnitude was found, while transmissivities did not change for HF3 and HF5. In case of HF3, it is likely that during HF, a fracture was initiated at weakness zones (i.e., biotite-rich bands) some $0.2-0.3 \mathrm{~m}$ outside the injection interval underneath the lower packer, explaining the low recovery rate (Table 1, Gischig et al., 2018). Hydraulic tests conducted $0.5 \mathrm{~m}$ below the HF3 interval suggest a transmissivity several orders of magnitude higher than in the HF3 interval, supporting this scenario (shown with HS in Figure 2). Similar behavior is also suspected for HF5 in SBH4: 
exceptionally high breakdown, reopening and shut-in pressures found during HF compared to the surrounding experiments, as well as nontypical pressure evolution during HF injections (see Figure S1, supporting information), indicate problematic fracturing conditions possibly related to a bypass around the packers. Besides HF3 and HF5 tests, we observe a 30- up to 380-fold transmissivity increase for the other six intervals.

The initial flow dimension estimated from PI tests (blue lines in Figure 2) varies from 0.4 to 2.3. For all experiments, flow dimensions increased after HF tests and reached values around $2 \pm 0.5$ (except for HF3). A flow dimension of 2 represents radial flow, which is expected for flow within a 2-D fracture surface. Note that changes in flow dimension for HF3 and HF5 tests cannot be interpreted. The HTPF is exceptional for the flow dimension that is 2 , both before and after the experiment, indicating that no significant change in the flow regime has occurred, despite a 240 -fold increase in transmissivity. This is consistent with the observation that a fracture network existed prior to the experiment. Thus, no new flow paths were opened, but existing ones were stimulated. For HF2, HF6, and HF7, the flow dimension increased from $\sim 1.5$ to $>2$. It is possible that these HF tests linked single small preexisting fractures to a 2D-3D fracture network. This concurs with the initial transmissivity of $\sim 10^{-11} \mathrm{~m}^{2} / \mathrm{s}$ in these intervals being 2 to 3 orders higher than in the intact rock. The initial flow dimension of HF1 and HF4 is $<1$ corresponding to sublinear flow, while after HF, the values increased to $\sim 1.5$ representing a mixture of linear and radial flow dimension.

For five tests (i.e., HF1, HF2, HF3, HF7, and HTPF), it was possible to derive the fracture dimension by analyzing the CRI tests using the Gringarten and Ramey (1974) solution. The other tests (HF4, HF5, and HF6) could not be analyzed as the method is only reliable for transmissivity $>10^{-11} \mathrm{~m}^{2} / \mathrm{s}$. Comparison between inferred fracture size from CRI tests and the seismicity clouds in Figure 2 shows excellent agreement. It should be mentioned that the Gringarten and Ramey solution estimates the radius of a single radial-symmetric fracture intersecting a borehole, while the radius of the seismicity clouds is based on the distance of the farthest seismic event from the injection point. However, seismicity does not present a radial pattern around the borehole. These observations will be discussed in the following section. Nonetheless, the agreement of these two fracture size estimates indicates that both transmissivity changes and seismicity are expressions of the same mechanism: shearing-related, irreversible deformation around and along the propagating fracture.

\subsection{Induced Seismicity}

During the eight tests, $\sim 7,500$ seismic events were detected. The number of detected events during individual experiments strongly varies and depends on the proximity of the injection interval to the borehole sensor array (Table 1). Therefore, it decreases from 2258 to 253 from HF4 to the HTPF experiment in SBH4, and from 1161 to 274 from HF1 to HF3 in SBH3. In contrast, the number of located events depends less on the interval position relative to the borehole sensors and ranges from 3 to $26 \%$ of all detected events per experiment. The seismicity clouds are shown in Figure 3. In case of SBH3, the seismicity clouds propagate a 4-5 m distance away from the injection point, predominantly in one direction away from the borehole-upward in case of HF1 and HF2 and downward in the case of HF3. The clouds show a consistent orientation of $175^{\circ} / 75^{\circ}$ (dip direction/dip). In the case of SBH4, the seismicity clouds propagate toward the east, away from the borehole and toward the tunnel. Here seismicity is more scattered and does not define clear oblate shapes, as in $\mathrm{SBH}$. It is unclear if the actual nature of seismicity is different in $\mathrm{SBH} 4$, or if this is related to the network configuration for $\mathrm{SBH} 4$, which has poorer spatial coverage than $\mathrm{SBH}$. Nevertheless, the seismicity clouds have diameters of 5-10 m, with the largest concentration of events within a $5 \mathrm{~m}$ diameter, which is comparable to $\mathrm{SBH}$. Unidirectional growth of seismicity clouds is observed for all HFs, although propagation direction varies between experiments and boreholes. It may be related to near-wellbore heterogeneities that define fracture initiation (e.g., flaws at one particular side of the borehole). The fractures would tend to propagate asymmetrically as fractures likely grow in the toughness-rather than in the viscosity-dominated regime. However, also stress gradients may explain asymmetric fracture growth (for instance, the consistent eastward growth in SBH4 toward the tunnel) as proposed by Dahm et al. (2010).

A moment magnitude $M_{w}$ was estimated for a total of 137 events (see supporting information), while the amplitude magnitude $M_{A}$ was computed for 1083 events. For events with an $M_{w}$ estimate, source radii were computed from moments and corner frequencies (Figure 3e, Madariaga, 1976). These range from 0.2 to $1.5 \mathrm{~m}$ and are largest for HF7 and HTPF close to the shear zone. Distributions of $M_{A}$ are compared for the different experiments in Figures $3 f$ and $3 g$. Deriving Gutenberg-Richter $a$ and $b$ values is problematic as the event numbers are limited, and the amplitude magnitudes only cover a narrow range between approximately 

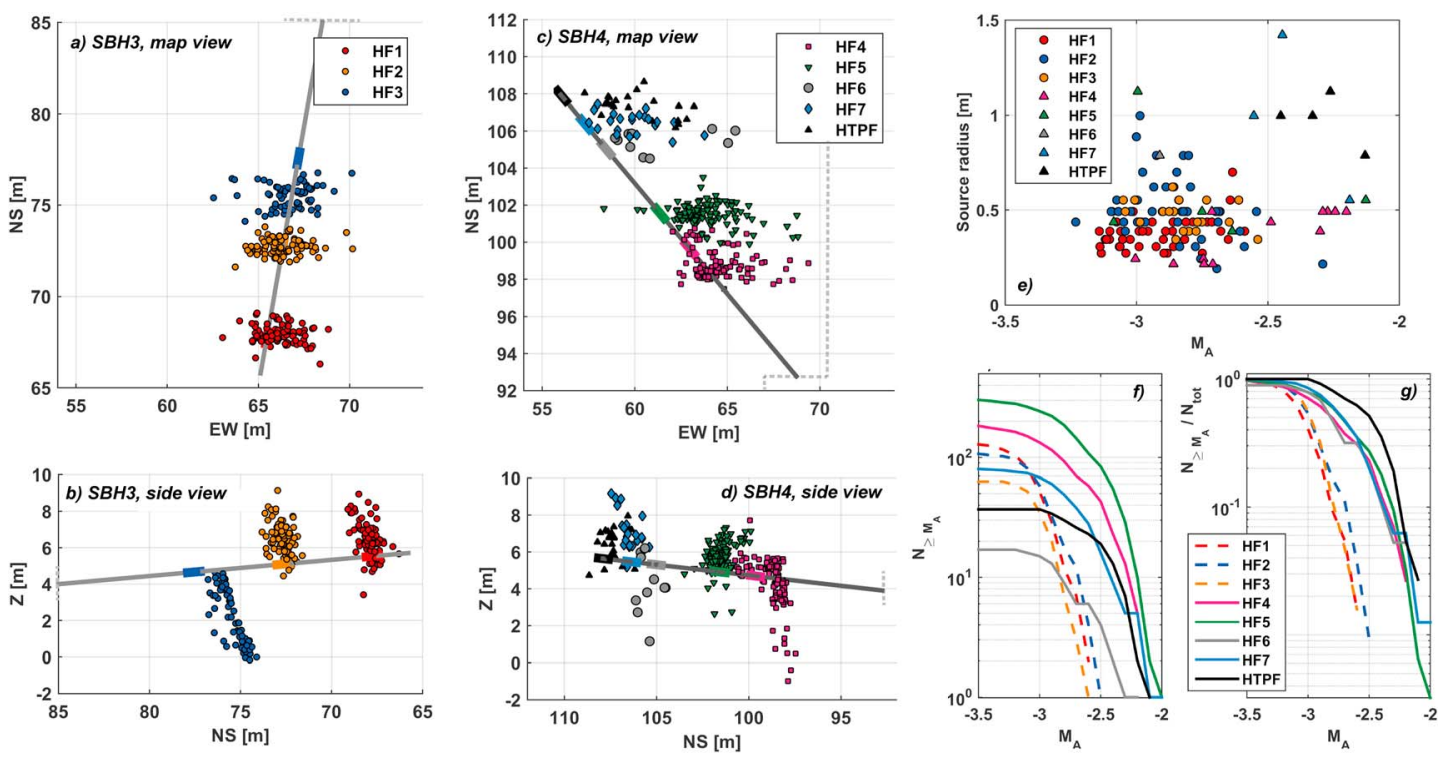

Figure 3. (a and b) Map and side view of seismicity clouds in SBH3. (c and d) Map and side view of seismicity clouds in SBH4. (e) Magnitude versus source radius estimated for a subset of events. (f) Magnitude distributions of all experiments. (g) Magnitude distributions normalized to total number of events per experiment.

-3.5 and -2.0 . Nevertheless, the distributions can be compared in a qualitative manner: The magnitude level is generally higher in SBH4 than in SBH3. The HTPF experiment stands out as it tends to have the most magnitudes around -2.5 compared to the others if the distributions are normalized to the total number of events per experiment. Comparing the experiments within $\mathrm{SBH} 4$, it is observed that most of the largest events $\left(M_{w}-2.6\right.$ to -2.0$)$ or the largest source radii $(>0.8 \mathrm{~m})$ come from the HF4, HF7, and the HTPF experiment. The latter two are the closest to the S3 fault. However, the difference in magnitude levels between SBH3 and SBH4 may also be an artifact of the different seismic networks for SBH3 and SBH4. It is noteworthy that the scaling between $M_{A}$ and $M_{w}$ is similar when comparing experiments of both boreholes (Figure S4 supporting information) and that the error of magnitude estimates is \pm 0.25 only due to potentially uncertain instrument responses. Not only the magnitude levels differ between SBH3 and SBH4 but so do the widths of the clouds (wider and more scatter in SBH4, narrow and well-defined in $\mathrm{SBH} 3$ ) and the propagation direction (eastward in $\mathrm{SBH} 3$, upward or downward in $\mathrm{SBH} 3$ ). One may speculate that these differences are related to the higher fracture density in SBH4 (Figure 2) leading to more scattered and stronger seismicity.

\section{Discussion}

Transmissivity measurements before and after HF and HTPF tests show that transmissivity can be enhanced by at least 2 to 3 orders of magnitude. These observations challenge the simplified model of tensile fracture opening and closing, suggesting little or no transmissivity change. The abundance of seismicity during our HF experiments (and reported by others, e.g., Zang et al., 2017) indicates that fracture propagation is associated with substantial energy dissipation and irreversible deformation. Many authors working on HF-induced seismicity report dominant double-couple source mechanisms as has also been found for our experiments in SBH3 (Gischig et al., 2018). They propose that seismicity is mostly related to slip along preexisting fractures which is triggered by pressure leak-off around the propagating fracture. The occurrence of seismicity is key to understanding the underlying mechanism of transmissivity enhancement during HF: Irreversible slip around the propagating fracture slightly deforms the surrounding rock. Thus, when the fracture closes after depressurization, the newly created fracture surfaces mismatch, resulting in an irreversible fracture opening. We argue that similar rock mass deformation and resulting transmissivity enhancement may also occur in large-scale HF operations, where decameter-long hydraulic fractures inevitably interact with preexisting fractures and faults. The contribution of hydraulic fractures in connecting wellbores to the formation may be underestimated, particularly in the context of EGS. 
A systematic correlation between transmissivity enhancement and event numbers, frequency-magnitude distribution, or maximum magnitudes is not visible, unlike what was suggested in the theoretical considerations made by Ishibashi et al. (2016) and Gischig et al. (2014). However, considering borehole SBH4 only, the largest transmissivity change occurs for the HTPF, where many of the largest seismic events have also occurred. Here larger transmissivity enhancement is conceived as preexisting fractures are stimulated, inducing slip and irreversible dilation. However, the largest enhancement, by a factor of 380, is observed for HF1 in $\mathrm{SBH}$. Perhaps these factors derived from PI tests only represent local effects around the borehole and thus strongly depend on structural conditions in the near-wellbore rock mass. However, we argue that the agreement between post-HF PI and CRI tests implies that the transmissivity change is not only a near-wellbore effect in the radius of influence of PI tests but also encompasses a larger radius. The observed change in transmissivity is representative for a radius of 5-10 $\mathrm{m}$ around the wellbore, based on the radius of influence of $\mathrm{PI}$ and CRI tests. Nevertheless, the observed transmissivity changes may also depend on where seismic events and irreversible slip occurs, relative to the boreholes. Our observations indicate that both transmissivity change and microseismicity strongly depend on local rock mass conditions (i.e., heterogeneities such as preexisting fractures).

\section{Conclusions}

The HF experiments in crystalline rock produced transmissivity increases of 2 to 3 orders of magnitude within the rock volume, several meters around the injection interval. We systematically compared seismicity characteristics and transmissivity changes but did not find a clear relationship, although seismicity rates varied strongly between experiments. However, we find strong correlation between fracture size derived from seismicity clouds and hydraulic responses. We argue that slip on pre-existing decimeter to meter-sized fractures is the underlying mechanism of both seismicity and irreversible transmissivity changes, which challenges simplified models treating hydraulic fractures as simple mode I dislocations on planar structures.

\section{Acknowledgments}

The ISC is a project of the Deep Underground Laboratory at ETH Zurich, established by the Swiss Competence Center for Energy Research - Supply of Electricity (SCCER-SoE) with the support of the Swiss Agency for Innovation Promotion (Innosuisse). Funding for the ISC project was provided by the ETH Foundation with grants from Shell and EWZ and by the Swiss Federal Office of Energy through a P\&D grant. Hannes Krietsch is supported by SNF grant 200021_169178. The Grimsel Test Site is operated by Nagra, the National Cooperative for the Disposal of Radioactive Waste. We are indebted to Nagra for hosting the ISC experiment in their GTS facility and to the Nagra technical staff for onsite support. All data are available through doi:10.3929/ethz-b-000217536 and doi:10.3929/ethz-b-000227499.

\section{References}

Amann, F., Gischig, V., Evans, K., Doetsch, J., Jalali, R., Valley, B., et al. (2018). The seismo-hydro-mechanical behaviour during deep geothermal reservoir stimulation: Open questions tackled in a decameter-scale in-situ stimulation experiment. Solid Earth, 9, 115-137. https://doi.org/ $10.5194 / \mathrm{se}-9-115-2018$

Ando, K., Kostner, A., \& Neuman, S. P. (2003). Stochastic continuum modeling of flow and transport in a crystalline rock mass: Fanay-Augeres, France, revisited. Hydrogeology Journal, 11(5), 521-535. https://doi.org/10.1007/s10040-003-0286-0

Arihara, N., Fukagawa, H., Hyodo, M., \& Abbaszadeh, M. (1995). Interpretation of pre- and post-fracturing well tests in a geothermal reservoir. Paper Presented at the 20th Workshop on Geothermal Reservoir Engineering, Stanford, CA.

Barker, J. A. (1988). A generalized radial flow model for hydraulic tests in fractured rock. Water Resources Research, 24(10), 1796-1804. https:// doi.org/10.1029/WR024i010p01796

Barker, J. A., \& Black, J. H. (1983). Slug tests in fissured aquifers. Water Resources Research, 19(6), 1558-1564. https://doi.org/10.1029/ WR019i006p01558

Cooper, H. H., Bredehoeft, J. D., \& Papadopulos, I. S. (1967). Response of a finite-diameter well to an instantaneous charge of water Water Resources Research, 3(1), 263-269. https://doi.org/10.1029/WR003i001p00263

Cooper, H. H., \& Jacob, C. E. (1946). A generalized graphical method for evaluating formation constants and summarizing well-field history. Eos, Transactions American Geophysical Union, 27(4), 526-534. https://doi.org/10.1029/TR027i004p00526

Dahm, T., Hainzl, S., \& Fischer, T. (2010). Bidirectional and unidirectional fracture growth during hydrofracturing: Role of driving stress gradients. Journal of Geophysical Research, 115, B12322. https://doi.org/10.1029/2009JB006817

Daviau, F., Mouronval, G., Bourdarot, G., \& Curutchet, P. (1988). Pressure analysis for horizontal wells. SPE Formation Evaluation, 3(04), 716-724. https://doi.org/10.2118/14251-PA

de Marsily, G. (1986). Quantitative hydrogeology; groundwater hydrology for engineers. San Diego, CA: Academic Press.

Doetsch, J., Krietsch, H., Lajaunie, M., Jordi, C., Gischig, V., Schmelzbach, C., \& Maurer, H. (2017). Characterizing fractures and shear zones in crystalline rock using anisotropic seismic inversion and GPR imaging. Paper presented at EGU General Assembly Conference Abstracts.

Dusseault, M., \& McLennan, J. (2011). Massive multistage hydraulic fracturing: Where are we. Paper Presented at 45th US Rock Mechanics/Geomechanics Symposium, San Francisco, CA.

Economides, M. J., \& Nolte, K. G. (2000). Reservoir stimulation (3rd ed.). New York: Wiley.

Evans, K. F., Genter, A., \& Sausse, J. (2005). Permeability creation and damage due to massive fluid injections into granite at $3.5 \mathrm{~km}$ at Soultz: 1. Borehole observations. Journal of Geophysical Research, 110, B04203. https://doi.org/10.1029/2004JB003168

Evans, K. F., Moriya, H., Niitsuma, H., Jones, R. H., Phillips, W. S., Genter, A., et al. (2005). Microseismicity and permeability enhancement of hydrogeologic structures during massive fluid injections into granite at $3 \mathrm{~km}$ depth at the Soultz HDR site. Geophysical Journal International, 160(1), 389-412. https://doi.org/10.1111/j.1365-246X.2004.02474.x

Falls, S. D., Young, R. P., Carlson, S. R., \& Chow, T. (1992). Ultrasonic tomography and acoustic emission in hydraulically fractured Lac du Bonnet granite. Journal of Geophysical Research, 97(B5), 6867-6884. https://doi.org/10.1029/92JB00041

Gidley, J. L., Holditch, S. A., Nierode, D. E., \& Veatch, R. W. Jr. (1989). Recent advances in hydraulic fracturing. SPE Monograph, $12,464$.

Gischig, V. S., Doetsch, J., Maurer, H., Krietsch, H., Amann, F., Evans, K. F., et al. (2018). On the link between stress field and small-scale hydraulic fracture growth in anisotropic rock derived from micro-seismicity. Solid Earth, 9, 39-61. https://doi.org/10.5194/ se-9-39-2018 
Gischig, V. S., Wiemer, S., \& Alcolea, A. (2014). Balancing reservoir creation and seismic hazard in enhanced geothermal systems. Geophysical Journal International, 198(3), 1585-1598. https://doi.org/10.1093/gji/ggu221

Gringarten, A. C., \& Ramey, H. J. (1974). Unsteady state pressure distributions created by a well with a single horizontal fracture, partial penetration or restricted entry. SPE Journal, 14(04), 413-426. https://doi.org/10.2118/3819-PA

Haimson, B. C., \& Cornet, F. H. (2003). ISRM suggested methods for rock stress estimation-part 3: Hydraulic fracturing (HF) and/or hydraulic testing of pre-existing fractures (HTPF). International Journal of Rock Mechanics and Mining Sciences, 40(7-8), 1011-1020. https://doi.org/ 10.1016/j.ijrmms.2003.08.002

Häring, M. O., Schanz, U., Ladner, F., \& Dyer, B. C. (2008). Characterisation of the Basel 1 enhanced geothermal system. Geothermics, 37(5), 469-495. https://doi.org/10.1016/j.geothermics.\%202008.06.002

Hart, D. (2016). A comparison of fracture transmissivities in granite water wells before and after hydrofracturing. Hydrogeology Journal, 24(1), 21-33. https://doi.org/10.1007/s10040-015-1315-5

Hubbert, M. K., \& Willis, D. G. (1972). Mechanics of hydraulic fracturing. AIME Transactions, 210, 153-168.

Illman, W. A. (2005). Type curve analyses of pneumatic single-hole tests in unsaturated fractured tuff: Direct evidence for a porosity scale effect. Water Resources Research, 41(4), W04018. https://doi.org/10.1029/2004WR003703

Illman, W. A., \& Tartakovsky, D. M. (2006). Asymptotic analysis of cross-hole hydraulic tests in fractured granite. Groundwater, 44(4), 555-563. https://doi.org/10.1111/j.1745-6584.2006.00201.x

Ishibashi, T., Watanabe, N., Asanuma, H., \& Tsuchiya, N. (2016). Linking microearthquakes to fracture permeability change: The role of surface roughness. Geophysical Research Letters, 43, 7486-7493. https://doi.org/10.1002/2016GL069478

Keusen, H. R., Ganguin, J., Schuler, P., \& Buletti, M. (1989). Grimsel Test Site-Geology. (Rep. NTB 87-14E). Baden: NAGRA.

Krietsch, H., Gischig, V., Jalali, M. R., Amann, F., Evans, K. F., Doetsch, J., \& Valley, B. (2017). Stress measurement in crystalline rock: Comparison of overcoring, hydraulic fracturing and induced seismicity results. Paper presented at the 51 st US Rock Mechanics / Geomechanics Symposium. San Francisco, CA

Kwiatek, G., Plenkers, K., Dresen, G., \& Group, J. R. (2011). Source parameters of picoseismicity recorded at Mponeng Deep Gold Mine, South Africa: Implications for scaling relations. Bulletin of the Seismological Society of America, 101(6), 2592-2608. https://doi.org/10.1785/ 0120110094

Le Borgne, T., Bour, O., de Dreuzy, J. R., Davy, P., \& Touchard, F. (2004). Equivalent mean flow models for fractured aquifers: Insights from a pumping tests scaling interpretation. Water Resources Research, 40(3), W03512. https://doi.org/10.1029/2003WR002436

Lee, H. S., \& Cho, T. F. (2002). Hydraulic characteristics of rough fractures in linear flow under normal and shear load. Rock Mechanics and Rock Engineering, 35(4), 299-318. https://doi.org/10.1007/s00603-002-0028-y

Madariaga, R. (1976). Dynamics of an expanding circular fault. Bulletin of the Seismological Society of America, 66(3), 639-666.

McClure, M. W., \& Horne, R. N. (2014). An investigation of stimulation mechanisms in Enhanced Geothermal Systems. International Journal of Rock Mechanics and Mining Sciences, 72, 242-260. https://doi.org/10.1016/j.jirmms.2014.07.011

Nolen-Hoeksema, R. C., \& Ruff, L. J. (2001). Moment tensor inversion of microseisms from the B-Sand propped hydrofracture, M-Site, Colorado. Tectonophysics, 336(1-4), 163-181. https://doi.org/10.1016/S0040-1951(01)00100-7

Park, Y.-J., Sudicky, E. A., McLaren, R. G., \& Sykes, J. F. (2004). Analysis of hydraulic and tracer response tests within moderately fractured rock based on a transition probability geostatistical approach. Water Resources Research, 40(12), W12404. https://doi.org/10.1029/ 2004WR003188

Rahman, M. K., Hossain, M. M., \& Rahman, S. S. (2002). A shear-dilation-based model for evaluation of hydraulically stimulated naturally fractured reservoirs. International Journal for Numerical and Analytical Methods in Geomechanics, 26(5), 469-497. https://doi.org/10.1002/ nag.208

Renard, P., Glenz, D., \& Mejias, M. (2009). Understanding diagnostic plots for well-test interpretation. Hydrogeology Journal, 17(3), 589-600. https://doi.org/10.1007/s10040-008-0392-0

Roberts, R. M. (2006). User's manual for nSIGHTS, Version 2.40 (p. 496). Carlsbad, NM, ERMS 544708: Sandia National Laboratories.

Roques, C., Bour, O., Aquilina, L., \& Dewandel, B. (2016). High-yielding aquifers in crystalline basement: Insights about the role of fault zones, exemplified by Armorican Massif, France. Hydrogeology Journal, 24(8), 2157-2170. https://doi.org/10.1007/s10040-016-1451-6

Rutledge, J. T., Phillips, W. S., \& Mayerhofer, M. J. (2004). Faulting induced by forced fluid injection and fluid flow forced by faulting: An interpretation of hydraulic-fracture microseismicity, Carthage Cotton Valley Gas Field, Texas. Bulletin of the Seismological Society of America, 94(5), 1817-1830. https://doi.org/10.1785/012003257

Rutqvist, J., \& Stephansson, O. (2003). The role of hydromechanical coupling in fractured rock engineering. Hydrogeology Journal, 11(1), 7-40. https://doi.org/10.1007/s10040-002-0241-5

Sanchez-Vila, X., Meier, P. M., \& Carrera, J. (1999). Pumping tests in heterogeneous aquifers: An analytical study of what can be obtained from their interpretation using Jacob's method. Water Resources Research, 35(4), 943-952. https://doi.org/10.1029/1999WR900007

Zang, A., Stephansson, O., Stenberg, L., Plenkers, K., Specht, S., Milkereit, C., et al. (2017). Hydraulic fracture monitoring in hard rock at $410 \mathrm{~m}$ depth with an advanced fluid-injection protocol and extensive sensor array. Geophysical Journal International, 208(2), 790-813. https://doi. org/10.1093/gji/ggw430

Zoback, M. D., \& Harjes, H.-P. (1997). Injection-induced earthquakes and crustal stress at 9 km depth at the KTB deep drilling site, Germany. Journal of Geophysical Research, 102(B8), 18,477-18,491. https://doi.org/10.1029/96JB02814 